\title{
COMERCIALIZAÇÃO DE ALIMENTOS NO CIRCUITO INFERIOR DA ECONOMIA URBANA: A VENDA NA RUA
}

\author{
FOOD COMMERCIALIZATION IN LOWER CIRCUIT \\ OF URBAN ECONOMY: SALE ON THE STREET
}

\author{
Alexandra Pava Cárdenas ${ }^{(*)}$ \\ Danton Leonel de Camargo Bini $i^{(*)}$ \\ Jhon Jairo Bejarano ${ }^{(* *)}$
}

\begin{abstract}
Resumo: Uma das atividades de comércio informal mais comum entre as populações de menor poder aquisitivo na América Latina é a venda de alimentos na rua. Além do entendimento de ser este um ofício garantidor da sobrevivência, enquanto parte integrante do circuito inferior da economia urbana, tal atividade apresenta perigos latentes para a saúde pública no que se referem tanto à procedência das matérias-primas quanto às práticas higiênicas das preparações que se comercializam. Associado a isso, existem preocupações sociais relacionadas aos temas subemprego, oportunidades de capacitação, vulnerabilidade social e ocupação do espaço público. Bogotá e São Paulo apresentam contrastes sociais que precisam de ações políticas que devem ir além da regulação e considerar os determinantes em saúde, ao incluir ações sociais efetivas.

Palavras-chave: Alimentos de rua, Circuitos comerciais, Políticas públicas, Bogotá, São Paulo.

Abstract: One of the activities more common among lower income populations in Latin America is the sale of street food in the informal commerce. Despite of this occupation is guarantee of survival, like a part of the lower circuit of the urban economy, also presents critical control points to public health in relation with origin of raw materials and hygienic practices in the preparations to be sold. Associated with this, there is a social preoccupation with underemployment, training opportunities, social vulnerability and occupation of public space. Bogotá and São Paulo have social contrasts that require policy actions that go beyond regulation and consider the determinants of health, including social actions.
\end{abstract}

Keywords: Street foods, Commercial circuits, Public policy, Bogotá, São Paulo.

$(*)$ Nutricionista Dietista formada pela Universidade Nacional da Colômbia, bolsista CNPq programa PEC-PG. Mestre em Nutrição pela Faculdade de Saúde Pública (FSP) da Universidade de São Paulo (USP). E-mail: <apavac@usp.br>.

$\left({ }^{* *}\right)$ Geógrafo, Pesquisador Científico do Instituto de Economia Agrícola (IEA) da Agência Paulista de Tecnologia dos Agronegócios (APTA). Doutorando em Geografia Humana pela Faculdade de Filosofia, Letras e Ciências Humanas (FFLCH) da Universidade de São Paulo (USP). E-mail: < danton@iea.sp.gov.br>.

$(* * *)$ Nutricionista Dietista, Professor Associado do Departamento de Nutrição da Faculdade de Medicina da Universidade Nacional da Colômbia (UNAL). Doutorando em Nutrição pela Faculdade de Medicina da Universidade de Buenos Aires (UBA). E-mail: <jjbejaranor@unal.edu.com>. 


\section{INTRODUÇÃO}

A teoria dos circuitos da economia urbana afirma que existem nos países pobres e "em desenvolvimento" dois circuitos responsáveis não só pelo processo econômico, mas também pelo processo de organização do espaço. Cada circuito é definido por um conjunto de atividades e pelo setor da população que está associado a esse, seja para os negócios ou para o consumo. De tal modo, o circuito superior refere-se aos setores bancário, comercial e industrial modernos, enquanto o circuito inferior consiste em atividades intensivas em mão de obra (não em capital) e por serviços e comércios não modernos (em pequenas dimensões) (SANTOS, 2002). Neste sentido, os circuitos da economia urbana são subsistemas que possuem relações de hierarquia e complementaridade, pois nas cidades não só existem mercados modernos (DI NUCCI, 2011) ${ }^{(1)}$.

O processo de formação socioespacial nos países em desenvolvimento manifestou-se no último século pela acelerada urbanização acontecida majoritariamente em aglomerações metropolitanas. De forma desordenada, este processo aconteceu com disparidades na divisão do trabalho que consequentemente contribui para a constituição dos diferentes circuitos espaciais de produção, distribuição e consumo das atividades econômicas. Em paralelo aos vetores mais modernos expandidos com o alargamento da globalização nas duas últimas décadas, as cidades milionárias e metrópoles do mundo mantêm em alta densidade a oferta de atividades produtivas, comerciais e de serviços, em geral de baixa capitalização, intensivas em mão de obra e com quase nenhuma organização sistemática (SANTOS, 2002).

Essa rápida urbanização levou ao desencadeamento de crescentes problemas também na mobilidade viária. Numa realidade em que as pessoas percorrem largas distâncias cotidianamente entre o lugar de trabalho e o domicílio, o surgimento e a manutenção dos comércios de alimentos baratos (às vezes, pouco nutritivos e de baixa higiene), nas ruas das grandes cidades manifestam situações características de um planejamento socioespacial direcionado predominantemente à reprodução do capital e não à reprodução saudável da vida em sociedade (CARDOSO, SANTOS \& SILVA 2009; ARAMBULO et al., 1995).

Os avanços tecnológicos e a globalização da economia impactaram na indústria de alimentos, na agricultura e no padrão de comensalidade contemporânea urbana: tudo isso se evidencia no que predominantemente é vendido na rua (GARCIA, 2003). Assim, essas transformações trazem como consequências alterações no perfil de morbimortalidade, o qual é objeto de preocupação, por um lado, das ciências da saúde com a questão de alimentos cada vez mais processados, com alta densidade energética e baixa qualidade nutricional (ENSIN, 2010; IBGE, 2010b) e, por outro da ciência econômica, no que se refere aos custos da saúde, os preços dos alimentos, as oportunidades laborais e a sustentabilidade populacional (FAO, 2010).

(1) Até mesmo as atuações modernas nos negócios urbanos não se apresentam homogeneamente. Daí a compreensão da existência de um circuito superior e um circuito superior marginal na economia urbana dos países menos desenvolvidos. Este último (superior marginal) se faz presente em posições intermediárias oscilando entre os polos extremos (BICUDO, 2006): mesmo capitalizados, atuam fazendo usos de tecnologias e arranjos organizacionais menos modernos, ocupando espaços urbanos nas franjas do tecido urbano (SANTOS, 2002). 
Dentro das tendências de modificação nos padrões de consumo alimentar, subsistem os setores da economia urbana que oferecem serviços na rua correspondentes ao circuito inferior. Estes atendem grande parte da população, prioritariamente a quem recebe baixos salários e tem acesso restringido na compra de alimentos em lugares formais (SANTOS, 2002). Estima-se que a venda de alimentos na via pública na América Latina e no Caribe constituirá um elemento importante a ser considerado na Segurança Alimentar e Nutricional (SAN) para as camadas populares partindo das estimativas de aumento progressivo do êxodo rural nas próximas décadas (OPS, 2005).

A discussão sobre o tema de venda de alimentos na rua traz consigo uma série de situações que envolvem diferentes temáticas. Além do debate sobre as Doenças Transmissíveis por Água e Alimentos (DTA), também aparecem assuntos relacionados com o subemprego, a ocupação do espaço público e a geração de resíduos sólidos e orgânicos (FAO/OPS, 1994). Daí o propósito deste artigo refletir sobre a venda de alimentos na rua no circuito inferior da economia urbana em Bogotá D. C. (Colômbia) e São Paulo (Brasil) e sua interação com os aspectos sociais e políticos.

\section{A VENDA INFORMAL DE ALIMENTOS NAS VIAS PÚBLICAS: OS CASOS DE BOGOTÁ E DE SÃO PAULO}

Bogotá e São Paulo são os centros econômicos da Colômbia e do Brasil, respectivamente, caracterizados por serem cidades de grande magnitude, longos deslocamentos e concentração de capital. Trazem consigo a questão do vendedor ambulante sob o viés de sua legalidade e do direito ao trabalho e ao uso do espaço público. Enquanto aspectos discutidos recorrentemente em cada nova administração municipal, os interesses sociais (tanto ao trabalho quanto à alimentação saudável) são negligenciados, refletindo a crise social e econômica do modelo de sociedade vigente.

Uma das sustentações da existência da venda nas ruas é a representação social do problema do desemprego e do subemprego experimentado pelos países da América Latina, especialmente nas suas maiores cidades (FAO/OPS, 1994). Daí que o comércio de rua no meio urbano é exercido principalmente por migrantes rurais de pequenas e médias cidades com baixa escolaridade que buscam nas grandes cidades mais oportunidades de emprego e melhoras nas suas qualidades de vida. No entanto, eles encontram poucas oportunidades porque precisam de qualificação e experiência, e, além disso, são mal pagos (BORJA, 2008). Desse modo, a maioria dos ambulantes não tem nenhuma ou pouquíssima instrução, constituindo-se em grande parte de analfabetos ${ }^{(2)}$.

Ao atuarem em sua maior parte na clandestinidade, a quantificação dos trabalhadores do circuito inferior da economia se apresenta como uma incógnita. Essa clandestinidade leva ao mesmo tempo à cumplicidade de alguns e à parceria com outros: o vendedor

(2) Em São Paulo, esse tipo de comércio é incentivado pelo poder público mediante autorizações que devam priorizar os deficientes físicos, os idosos ou aqueles que, por uma ou outra razão, não podem concorrer no mercado de trabalho (TRIBUNAL DE JUSTIÇA DO ESTADO DE SÃO PAULO, 2012). Contudo, submerso predominantemente na informalidade, o comércio de alimentos no circuito inferior da economia urbana acaba sendo ocupação que inclui de forma majoritária o trabalho infantil, o de jovens e o de adultos, todos eles excluídos do acesso a uma educação de qualidade (BORJA, 2008; MENESES, 2010). 
muitas vezes depende de fornecedores também clandestinos e de fiscais públicos tolerantes e/ou corruptos. Assim, as mercadorias são fornecidas e comercializadas sem notas fiscais e garantias ${ }^{(3)}$ sob o olhar complacente de alguns fiscais municipais e policiais encarregados de reprimir o contrabando (Viva o centro São Paulo, 1994; MENESES, et al., 2010; GARCÍA-UBAQUE, RIAÑO-CASALLAS \& BENAVIDES-PIRACÓN, 2012).

Quadro 1 - Indicadores socioeconômicos

das cidades de Bogotá e São Paulo (2010)

\begin{tabular}{|l|r|r|}
\hline \multicolumn{1}{|c|}{ Indicador } & \multicolumn{1}{c|}{ Bogotá } & \multicolumn{1}{c|}{ São Paulo } \\
\hline População & $7.363 .782,0^{(\mathrm{a})}$ & $11.253 .503,0^{(\mathrm{b})}$ \\
\hline \% crianças (0 a 9 anos) & $16,2^{(\mathrm{a})}$ & $14,1^{(\mathrm{b})}$ \\
\hline \% adolescentes (10 a 19 anos) & $17,4^{(\mathrm{a})}$ & $16,4^{(\mathrm{b})}$ \\
\hline \% idosos (maiores de 60 anos) & $9,6^{(\mathrm{a})}$ & $11,9^{(\mathrm{b})}$ \\
\hline Densidade populacional (hab./km²) & $4.146,0^{(\mathrm{a})}$ & $7.387,7^{(\mathrm{b})}$ \\
\hline Taxa de desemprego (\%) & $10,7^{(\mathrm{c})}$ & $11,2^{(\mathrm{d})}$ \\
\hline
\end{tabular}

Fonte: ${ }^{(a)}$ DANE, 2009; ${ }^{(b)}$ IBGE, 2010a; (c) DANE, 2011; ${ }^{(d)}$ PED:2010.

Para entender melhor a situação da realidade deste estudo de caso, é preciso descrever o panorama geral das cidades objetos desta reflexão (Quadro 1). Daí, ao se fazer um paralelo vê-se que Bogotá e São Paulo são cidades metropolitanas que apresentam dados percentuais bem parecidos no que se refere ao número de crianças, adolescentes, idosos e pessoas desempregadas. Diferenciam-se demograficamente no fato de São Paulo ter uma maior densidade populacional, ao ser uma cidade mais verticalizada.

$\mathrm{Na}$ constituição dos espaços de venda de alimentos nas ruas, em Bogotá, a absorção do fluxo de desabrigados ${ }^{(4)}$ gerado pela violência em outras regiões do país contabiliza 200 mil pessoas por ano - numa media diária de 50 novos desabrigados na capital colombiana $^{(5)}$ (CODHES, 2012) — , conformando um contingente populacional que sem segurança permanente da sua renda encontra no circuito inferior da economia as únicas oportunidades tanto de emprego quanto de acesso à alimentação. Historicamente, o mesmo aconteceu em São Paulo, dando-se maior ênfase aos migrantes nordestinos das classes populares, que sem instrução encontraram no comércio ambulante uma das poucas opções de geração de renda para a subsistência ${ }^{(6)}$.

Em Bogotá, tem-se trabalhado muito para a realocação e legalização dos espaços públicos de atuação do comércio de rua. A partir de um cadastro na prefeitura, busca-se

(3) Exceto a frágil garantia dada pela palavra do vendedor: "... qualquer coisa pode trazer aqui que eu troco" no famoso ditado popular "Te dou meu fio do bigode".

(4) Também chamados de "refugiados".

(5) A Colômbia é considerada um dos países com o maior número de desabrigados por violência no mundo. As cifras históricas registram perto de 400.000 refugiados e quatro milhões de desabrigados internos por causa do conflito armado (ACNUR, 2012). No primeiro semestre do ano 2011, aproximadamente, 89.759 pessoas foram obrigadas a sair das suas regiões, sendo que os cinco municípios mais afetados pela recepção de desabrigados incluíram: Medellín-Antioquia com 14.902 (16,6\% ); Bogotá, D. C. com 11.215 (12,5\%); Amalfi-Antioquia com 5.941 (6,6\%); Anorí-Antioquia com 5.924 (6,6\%); e Tumaco-Nariño com 3.857 (4,3\%) (CODHES, 2012).

(6) No caso específico da venda de alimentos nas ruas, também reforça a manutenção deste mercado as 13.666 pessoas em situação de rua na cidade de São Paulo (SÃO PAULO, 2010). 
designar os espaços aptos para este tipo de atividade: daí a escolha de pontos perto das estações de transporte e em regiões de recuperação urbana (IPE, 2012).

No que corresponde a São Paulo, a permanência de comerciantes de rua (os chamados camelôs ${ }^{(7)}$ ) é regularizada por meio de um cadastro chamado TPUs (Termos de Permissão de Uso) em lugares específicos da cidade. Pagam-se taxas em razão das permissões, de forma que seus endereços residencial e comercial são conhecidos pela administração. Contudo, muitos sem permissão atuam na clandestinidade em ambas as metrópoles.

Assim, o que se vê em ambas as cidades é a manifestação de uma problemática que não pode ser abordada sob uma estreita visão individualista, pelos efeitos não só da ocupação do solo enquanto mercadoria, senão também pela visualização de sua função social ao gerar emprego e renda. Seguindo esta abordagem, conclui-se que a extinção de ambulantes significaria aumentar as cifras de desemprego (TRIBUNAL DE JUSTICA DO ESTADO DE SÃO PAULO, 2012) e de insegurança alimentar.

Daí que, ao se discutir a permissão do comércio nas ruas, a venda de alimentos se apresenta como um capítulo em separado. Diferentes dos bens duráveis (não perecíveis), os alimentos são veículos de nutrientes e também de microrganismos patógenos, ou seja, não só é o intercâmbio de produtos por dinheiro.

Entendendo que o comércio de alimento na rua implica desde a preparação das refeições no local da venda até a comercialização e o consumo propriamente dito, precisam-se reforçar nos regulamentos públicos de permissão destas atividades quais as infraestruturas básicas que garantam condições higiênico-sanitárias que protejam tanto comerciantes quanto consumidores da contaminação causada pelo mau manuseio dos alimentos.

Calculou-se que para o ano de 1995 aproximadamente entre 25 a 30\% do gasto em alimentos na América Latina e no Caribe eram destinados a produtos comercializados de forma ambulante (COSTARICA \& MORON, 1996) nas ruas do circuito inferior da economia urbana. Em Bogotá, mesmo com os investimentos entre 2010 e 2012 na ordem de U\$ 55 milhões de dólares em campanhas pedagógicas para que as pessoas não comprem alimentos de rua (IPE, 2012), a comercialização de refeições (incluindo fast food e frutas) é a que concentra o maior número de ambulantes e representa 39,7\% do total ${ }^{(8)}$ (CÁMARA DE COMERCIO DE BOGOTÁ, 2009a). Em São Paulo, a cidade mais cara das Américas (MERCER, 2012), a refeição feita em barracas e tendas de rua em geral é mais barata que a oferecida em restaurantes e lanchonetes inspecionados. Assim, estima-se que 18,6\% da renda da população s]ao investidas em refeições fora de casa ${ }^{(9)}$ (IBGE, 2010b) $^{(10)}$.

Do ponto de vista sanitarista, identifica-se a situação de venda de alimentos na via pública como controvertida por comercializar alimentos accessíveis para uma parcela da população, mas que ao mesmo tempo gera riscos potenciais à saúde relacionados com

(7) Do termo em francês camelot, vendedor de artigos de pouco valor.

(8) Arepa (tortilha de milho), salpicón (salada de frutas) e pacotes de salgadinhos e doces hegemonizam a paisagem das vendas de alimentos nas calçadas bogotanas.

(9) Estes dados oficiais, contudo, não especificam o quanto deste montante corresponde ao consumo de alimentos de rua.

(10) Outro estudo aponta que 55\% dos paulistanos realizam as principais refeições fora do lar. Dessas, $15 \%$ correspondem ao café da manhã, 30\%, ao almoço e 10\%, ao jantar. No café da manhã, $80 \%$ dos alimentos consumidos são pães, torradas, manteiga, margarina, café e leite integral. Já no almoço, 70\% do consumo correspondem a arroz, feijão, carne bovina, verduras, legumes, refrigerantes e aves. Enquanto isso, no jantar, os dados apontam $70 \%$ do consumo entre salgados, sanduíches, arroz, verduras, legumes, carne bovina, aves, refrigerante e suco de frutas (GORGULHO, 2012). 
doenças - entendidas na saúde pública como Doenças Transmitidas por Alimentos (DTA) - fruto das deficientes práticas de higiene.

Dessa forma, estudos feitos em cidades africanas e asiáticas concluíram que a comida feita e vendida nas ruas ou em mercados geralmente contribui na SAN da população no que se refere à disponibilidade e acesso, por ser de fácil aquisição, relativamente barata e que satisfaz a fome imediata (STEIN \& LABADARIOS, 2011). Entretanto, a SAN também inclui, dentro do conceito de qualidade, que a alimentação seja segura para o consumo humano, sendo um desafio esclarecer a causalidade das DTA porque diante de um evento de intoxicação alimentar é difícil apontar exatamente o lugar de fornecimento. Daí, afirmar que a venda de um alimento na rua é a origem da intoxicação precisa de estudos complementares que compreendem: atendimento médico, inspeção sanitária, investigação da origem do surto, análise das amostras, identificação dos agentes causais, entre outros (FAO/OMS, 2003).

Para o caso latino-americano analisado aqui, em nível epidemiológico é preocupante o número de casos registrados a cada ano. Evidências da ocorrência do evento ou da notificação aos sistemas de vigilância em saúde pública (sem contabilizar o sub-registro de casos) de DTA, Doenças Diarreicas Agudas (DDA), e casos de Hepatite A são verificados em Bogotá(11) e São Paulo ${ }^{(12)}$ (Quadro 2).

Quadro 2. Coeficientes de incidência Indicadores epidemiológicos por 100.000 habitantes nas cidades de Bogotá e São Paulo (2010)

\begin{tabular}{|l|r|r|}
\hline \multicolumn{1}{|c|}{ Indicador } & \multicolumn{1}{c|}{ Bogotá } & \multicolumn{1}{c|}{ São Paulo } \\
\hline Surto de DTA & $2,2^{(\mathrm{a})}$ & $1,7^{(\mathrm{b})}$ \\
\hline Casos DTA & $28,8^{(\mathrm{a})}$ & $8,7^{(\mathrm{b})}$ \\
\hline Casos DDA & $6.652,6^{(\mathrm{a})}$ & $1.681,5^{(\mathrm{b})}$ \\
\hline Casos Hepatite A & $6,4^{(\mathrm{a})}$ & $0,8^{*(\mathrm{~b})}$ \\
\hline
\end{tabular}

Fonte: ${ }^{(a)}$ SDS, 2011; ${ }^{(b)}$ CVE, 2012.

Disso se diagnostica que o número de doenças causadas por possíveis falhas na segurança dos alimentos e da água é alto e permanece desconhecido o agente causador na maioria dos casos em razão do fato de que o afetado tardiamente reporta a situação ou a equipe médica falha no seguimento dos protocolos estabelecidos (SDS, 2011; MINISTÉRIO DE SAÚDE, 2011).

A contaminação dos alimentos geralmente acontece pela ausência de higiene em sua manipulação (limpeza das mãos e dos utensílios utilizados para sua confecção e consumo), bem como por contaminações características de ambientes insalubres. Estudos na América Latina revelam que os principais riscos à saúde nestes estabelecimentos se relacionam às seguintes condições: preparação de comida sem acesso à água potável; desrespeito pelas

(11) Demonstrando casos de contaminação, na capital colombiana, um estudo identificou a presença de Salmonella em alimentos vendidos nas proximidades das universidades em Bogotá: das 42 amostras, 18 apresentaram crescimento do microrganismo (MÉNDEZ et al., 2009). Outro estudo realizado na região norte da cidade fez durante 15 dias o levantamento de 68 amostras de alimentos e foi reportada a presença de Salmonella e E. Coli respectivamente em $11,8 \%$ e $25 \%$ dos dados analisados (BAYONA, 2009).

(12) No Brasil, é importante destacar o trabalho que vem acontecendo principalmente em São Paulo com relação à pesquisa sobre a venda de alimentos na rua, sob uma abordagem tanto social como microbiológica dos vendedores (CARDOSO $\&$ SANTOS \& SILVA, 2009; BECERRA, 2008). 
práticas mínimas de higiene na preparação adequada dos alimentos; falta de cuidado na seleção de alimentos crus e negligência com a contaminação ambiental (FAO, 2010).

Em Bogotá, de acordo com o Sistema de Vigilância Epidemiológica (SIVIGILA) com relação aos locais de ocorrência de surtos notificados de DTA, 23\% foram em casa, 12\%, em instituições educativas, 5\%, em restaurantes e 4\%, na via pública. No caso dos tipos dos alimentos implicados nas contaminações, os resultados foram variados, destacando-se as preparações que possuem vários ingredientes — os alimentos mistos — (42\% do total), frango (7\%), mistura com arroz (6\%), comidas rápidas (6\%) e carne vermelha (5\%) (BOGOTÁ, 2011). No que corresponde a São Paulo, os alimentos que mais se têm associado às DTA são sanduíches, embutidos, carnes, salgadinhos, queijos, bolos e doces comercializados por ambulantes (SÃO PAULO, 2011). Em especial, o cachorro-quente tem sido bastante estudado ao representar um dos alimentos que mais incrementos obteve nas vendas de rua da maior metrópole brasileira (LUCCA \& TORRES, 2006).

De acordo com um relatório da Organização Pan-Americana da Saúde (OPAS), Bogotá é classificada como uma das capitais latino-americanas em que a demanda por alimentos de rua é maior, em diferentes estratos socioeconômicos (OPS, 1992). Adolescentes, jovens e adultos são aqueles que mais consomem alimentos nas ruas de Bogotá. Isso se justifica especialmente para quem tem extensos horários acadêmicos, de trabalho e encontra-se longe de casa (assim, gastam menos tempo na preparação de refeições).

E quanto ao consumo de alimentos em estabelecimentos fora do lar, segundo as projeções populacionais, na capital colombiana $65,7 \%$ das pessoas têm o hábito de adquirir comida nas ruas: 8,8\% têm entre 15 e 19 anos; $17,1 \%$, entre 20 e 29 anos e um total de $39,8 \%$ são adultos com idade entre 30 a 59 anos (DANE, 2009).

No caso do Brasil, as pesquisas mencionam que a alimentação fora de casa corresponde a 16\% das calorias dos alimentos consumidos (BRASIL, 2012). No caso da Colômbia, o Inquérito Nacional da Situação Nutricional (ENSIN, 2010) apresentou a venda de alimentos ambulantes como principal fonte energética da população: daí comidas rápidas, frituras e frutas são 39,5\% do consumido pelos colombianos nas ruas; 25,3\% o fazem diariamente, sendo Bogotá a região onde mais se consome, com 30,1\% da população (ENSIN, 2010).

\section{REGULAMENTOS TÉCNICOS E ADMINISTRATIVOS E DTA NA VENDA DE ALIMENTOS}

A regulação da venda de comida nas ruas, mesmo com a complexidade dos aspectos relacionados à conformação e à continuidade do segmento, configura-se como um avanço entre as estratégias propostas para o setor, tanto no uso do espaço público quanto no controle sanitário. Embora a decisão de regulação constitua uma das questões mais difíceis no delineamento do processo de intervenção, representa também uma base legal para o reordenamento do comércio de comida na rua e um apoio ao processo de descentralização de ações em saúde pública, gerando ou consolidando regulamentos municipais com base em normas nacionais. Assim, partindo da normatividade sobre a venda de alimentos em espaços públicos, as políticas em saúde pública devem executar ações em busca de proteger os consumidores e promover a alimentação saudável. Neste contexto, espaços próprios devem ser planejados e oferecidos, atendendo requisitos de funcionamento como o suprimento de água e energia, infraestrutura, instalações sanitárias e serviço de coleta de lixo (CARDOSO \& SANTOS \& SILVA, 2009). 
Fugindo desta perspectiva, em Bogotá, a Lei n. 1.480 de 2011, não inclui os princípios gerais do consumidor, especialmente no que se refere à proteção e à segurança contra os riscos para a saúde de comidas vendidas nas ruas (COLOMBIA, 2011): daí não se poder reclamar qualidade e garantia de uma atividade econômica colocada na informalidade, independente das funções da vigilância e controle de alimentos realizados pelo Instituto Nacional de Monitoramento de Drogas e Alimentos (INVIMA).

No intuito de formalizar estas atividades, aspectos que são abordados com veemência pelos críticos diz respeito ao treinamento em Práticas de Manipulação dos trabalhadores que vendem alimentos na rua e a implementação do Sistema de Vigilância Alimentar e Controle para desenvolver ações de melhoria, notificação, estudo e monitoramento da saúde dos consumidores. Disso objetiva-se consolidar sistemas de informações que forneçam os insumos necessários para a tomada de decisões e a definição de políticas públicas imersos nos planos nacionais e de desenvolvimento distrital e dos respectivos planos de saúde públicos e do estatuto do consumidor (COLOMBIA, 2011).

$\mathrm{Na}$ Colômbia, as normas técnicas aplicadas a este problema sensível à sociedade foram inicialmente abordadas de maneira superficial na Lei n. 9, de 1979, do Código Nacional de Saúde. Em seguida, de forma mais efetiva, o Decreto Distrital n. 1.048, de 1986, fez provisões aos vendedores de rua em pontos fixos de Bogotá e propôs um censo a fim de garantir o direito de se oferecer as licenças apropriadas para esses comerciantes até então informais e para os agentes públicos serem capazes de realizar os monitoramentos destes estabelecimentos.

Posteriormente, o governo nacional em 1993 aprovou a Resolução n. 604 que orientou quais as condições sanitárias para as atividades de vendas de alimentos em áreas públicas. Contudo, mais tarde, em 1997, o Ministério da Saúde, através do Decreto n. 3.075, de 1997, ao regulamentar as Boas Práticas de Manipulação não fez menção à venda de alimentos de rua, ou seja, somente se referenciou as indústrias em geral e os pontos de venda formais (como restaurantes e lanchonetes). Caso semelhante ocorreu com o Decreto n. 60, de 2002, quando se estabeleceu o Sistema de Análise de Perigos e Pontos Críticos de Controle (APPCC).

Em Bogotá, num período mais recente, estabeleceram-se diretrizes de atividades de controle de biossegurança e vigilância epidemiológica por parte da Secretaria Distrital de Saúde em restaurantes e em "barracas" de alimentos nas ruas da capital colombiana segundo o Projeto n. 160, de 2004, do Conselho para a Vigilância. Também no mesmo ano foi elaborado o Decreto Distrital n. 98, que emitiu normas relativas à preservação do espaço público e sua harmonização com os direitos dos vendedores ambulantes que o ocupam (CÁMARA DE COMERCIO DE BOGOTÁ, 2009b).

Assim, na linha de intervenção do consumo de alimentos sadios e seguros em Bogotá, o atributo da inocuidade se inclui no propósito de diminuir as doenças e melhorar as capacidades institucionais e de infraestrutura em geral dos estabelecimentos, com ênfase também para o caso da venda na rua (BOGOTÁ, 2011). Daí que os futuros planos maestros de abastecimento e SAN devem ter como objetivo geral garantir o fornecimento de alimentos de qualidade e em quantidade suficiente e estável, o que inclui a adoção de boas práticas agrícolas por parte dos produtores de alimentos no campo, de boas práticas de 
fabricação na indústria de processamento e, por fim, de boas práticas de manuseio dos alimentos por parte dos comerciantes em estabelecimentos de toda a natureza (SDS, 2011).

Por sua parte, no Brasil, todo o sistema de controle e fiscalização relacionado à higiene dos alimentos está amparado na Lei n. 2.312, de 1954, o Código Nacional de Saúde (documento-guia sobre a questão sanitária no Ministério de Saúde) e no Decreto-lei n. 986, de 1969, que institui normas básicas sobre as Boas Práticas de manipulação dos alimentos (BEZERRA, 2008).

Contudo, de forma geral, no país, até 2004 — quando a Agência Nacional de Vigilância Sanitária (ANVISA) passa a possuir uma estrutura mínima de atuação — não havia legislação federal regulamentadora para a atividade. Entretanto, desde 1990, com a implantação do Sistema Único de Saúde (SUS) e a descentralização das suas ações, o controle sanitário desse segmento passou a ser responsabilidade dos municípios ${ }^{(13)}$. Com isso, enquanto alguns municípios avançaram na elaboração de normas próprias (como Curitiba, Natal e São Paulo) muitos sequer alcançaram a organização dos seus serviços de Vigilância Sanitária (GERMANO \& GERMANO, 2011).

Posteriormente, o Ministério da Saúde, por meio da Resolução da Diretoria Colegiada n. 218, de 2005, dispôs sobre o regulamento técnico de procedimentos higiênico-sanitários para manipulação de alimentos e bebidas. Esse apresenta os formatos legais em relação às condições das localidades de comercialização de alimentos, definidas como instalação fixa, provisória ou ambulante ${ }^{(14)}$.

O município de São Paulo executa um tratamento bastante vigilante tanto em relação aos locais de comércio de refeições (lanchonetes, restaurantes e demais tipos de serviços de alimentação), quanto aos fornecedores de ingredientes (LANGE, 2010) ${ }^{(15)}$. Dentro dos antecedentes próprios do município, tem-se variado de forma seletiva a regulamentação sobre a venda de alimentos nas ruas. O Decreto n. 27.619, de 1989, autorizou o exercício de atividades de venda em vias públicas, porém, com vetos para o comércio de pastéis, embutidos, churrasquinhos, entre outros.

Agora, no que corresponde à venda de alimentos in natura e não preparados, segundo dados de 2012 da Secretaria Municipal de Coordenação das Subprefeituras, a capital paulista se destaca com a existência de 857 feiras livres (numa média de 122 feiras diárias) que leva para toda a cidade alimentos tipo carnes, ovos, legumes e frutas ${ }^{(16)}$. Destacam-se, entremeadas em pontos estratégicos da feira, enquanto comércios de alimentos preparado no local, as já tradicionais barracas de pastéis.

(13) Muitas destas atuações foram fortemente reforçadas pela Lei n. 8.078, de 1990 (o Código de Defesa do Consumidor), que ao mencionar a proteção da vida e da saúde com relação ao risco de práticas perigosas e nocivas, serve desde então como instrumento para o controle sanitário dos comércios de alimentos (BRASIL, 1990).

(14) No que se refere ao controle da contaminação microbiana, encontram-se estabelecidas ações nas mais distintas regiões, destacando-se aquelas ligadas às preparações da culinária regional e local que ocupam as ruas das grandes cidades brasileiras. Exemplo disso, o cachorro-quente paulista tem sido objeto de várias pesquisas (LUCCA \& TORRES DA SILVA, 2010).

(15) Como exemplo, têm-se o caso dos açougues en que é obrigatório o respaldo da qualidade da carne por um médico-veterinário, e o de alguns restaurantes em que o nutricionista é o encarregado por garantir a qualidade dos alimentos.

(16) Num total de 16.305 barracas em toda capital, a zona leste (como região mais povoada de São Paulo), destaca-se ao concentrar o maior percentual de feirantes. 
Em 1998, uma nova lei (regulamentada em 2002) normalizou o ofício dos "dogueiros motorizados" (como são chamados os vendedores que usufruem de uma infraestrutura de preparação de cachorros-quentes acoplada aos automóveis), na qual o comerciante deve usar luvas descartáveis e ter um ponto de água potável e um recipiente frigorífico. Fica, neste caso, sob a incumbência da prefeitura o cadastro, o treinamento, a fiscalização e definição dos lugares com permissão dos ambulantes comercializarem (BEZERRA, 2008) ${ }^{(17)}$.

Daí que, a partir de todos estes encaminhamentos realizados nas metrópoles Bogotá e São Paulo, compreende-se que os órgãos que regem as políticas em saúde pública devem se preocupar com os riscos potenciais gerados pelas vendas de alimentos na rua. Em virtude da falta de demanda e flexibilidade no cumprimento das regulamentações de saúde, esta forma de comercialização cresceu junto com as grandes aglomerações urbanas dos países em desenvolvimento e se reproduziu em outras cidades com pouquíssimo controle.

Notou-se que quando se fala de alimentos em vias públicas, a maioria das pesquisas realiza abordagens clínicas, como aquelas que retratam a contaminação por microrganismos (OPS, 1992). Os alimentos que têm sido mais pesquisados são aqueles mais ofertados, e, desta forma, são os que possuem potencialmente maior fonte de riscos de transmissão de doenças à população: cachorro-quente, arepa, hambúrguer, chouriço, empanada, ovo cozido, salada de frutas, lechona (preparação com carne de porco), churros e torresmo (BAYONA, 2009; BEZERRA, 2008).

Mesmo com estes estudos, as atividades voltadas para a melhoria da qualidade e inocuidade dos alimentos constituem-se como uma dívida que se tem com a sociedade, não só para assegurar a supervisão de processos e o controle de riscos à saúde pública, mas também para aumentar o desenvolvimento econômico de microempresas em famílias de baixa renda e baixa escolaridade, reconhecendo e formalizando o circuito inferior da economia urbana nos países em desenvolvimento no setor da alimentação. É preciso desenvolver projetos de grande dimensão, a partir de uma análise do território e da população que atenda às necessidades de informação e, portanto, capaz de influenciar as políticas públicas sobre o tema debatido. Assim, como refere Florez \& Mazuera (1998), a aplicação de um estudo descritivo seria útil, contudo, há lacunas no reconhecimento destes eventos de saúde pública em conjunto com as variáveis epidemiológicas de tempo, lugar e pessoa. Daí que a observação e o treinamento de pesquisadores são fundamentais na garantia da informação de qualidade, tanto para descrever os fatores de risco e identificar as necessidades de uma população, como para fornecer uma base de dados direcionada ao planejamento dos serviços de saúde e ao desenvolvimento de normas e procedimentos.

\section{CONSIDERAÇÕES FINAIS}

O posicionamento de Bogotá e São Paulo diante da venda de alimentos na rua tem algumas diferenças. Por um lado, na capital colombiana, ao mesmo tempo em que

(17) Por sua parte, a Câmara de Vereadores de São Paulo diz que dois projetos que tratam da legalização de quatro itens de alimentação vendidos nas ruas estão em discussão. Um deles pretende regularizar a venda de pastel e caldo de cana no entorno de estádios de futebol. Outro propõe a legalização da venda de algodão-doce e de pipoca. Nenhuma dessas discussões, entretanto, abrange a comida de rua de maneira geral. Já a Prefeitura de São Paulo afirma que não propôs projetos que discutam a venda de comida de rua nos últimos anos (FOLHA DE S. PAULO, 2012). Com a nova gestão do Partido dos Trabalhadores (PT) iniciada em janeiro 2013 na capital paulista, conversas realizadas com vendedores ambulantes em geral indicam uma expectativa de maior liberação da atividade. 
se tenta executar planos de melhorias nas condições dos vendedores de rua, aplica-se investimentos em programas para desestimular a compra de seus produtos. Por sua vez, em São Paulo, mesmo com a ausência de ações que sedimentem normativas na prática do cotidiano da metrópole (principalmente em sua periferia), existe um marco legal que permite a venda em lugares específicos com regularização para alguns produtos. Contudo, em ambos os municípios não se efetivou um processo que retrate o problema da venda de alimentos na rua em sua totalidade: com a existência de um percentual significativo de mão de obra pouco qualificada à margem do mercado formal, combater a manutenção de um circuito inferior da economia urbana para a alimentação torna-se algo quase inviável nestas metrópoles. Muitas pessoas de baixa renda dispõem, em seus extensos deslocamentos nestas grandes aglomerações urbanas, de pouquíssimo dinheiro para se alimentar, realidade essa que vai ao encontro do oferecido pelos ambulantes na rua, sem quase nenhuma exigência relacionada às normativas fitossanitárias. Daí que além de ser um problema de saúde pública, o comércio de alimentos nas ruas relaciona-se à realidade socioeconômica destas localidades.

Em busca de um controle mais efetivo desta atividade, seria importante identificar as condições de trabalho dos trabalhadores informais, segundo seus grupos de idade, sexo, local de origem, formação acadêmica, pertencimento a grupos especiais, entre outros. Assim, deve-se procurar conhecer como funciona a dinâmica da venda de alimentos de rua a partir de diferentes áreas do conhecimento e não apenas do ponto de vista do risco de contaminação, tendo em conta que este é um problema transversal e tem impactos sobre o estado de saúde e nutricional da população (de forma aguda em relação aos perigos microbiológicos e em longo prazo com o aparecimento de doenças crônicas). Além disso, é importante dar respostas a partir da perspectiva do trabalho e seu impacto na qualidade de vida dos habitantes.

Torna-se urgente também a análise dos determinantes sociais e a definição das relações que são tecidas para a formulação dos padrões de políticas de desenvolvimento, políticas de saúde do trabalho, SAN, de educação, redes sociais e as avaliações dos resultados analíticos do processo saúde-doença, seus conhecimentos, crenças, atitudes e práticas.

\section{REFERÊNCIAS BIBLIOGRÁFICAS}

ACNUR-Agencia de la ONU para refugiados. Desplazamiento: el nuevo reto del siglo XXI. Tendencias globales 2012. Disponível em: <http://www.acnur.org/t3/fileadmin/scripts/doc.php?file=t3/fileadmin/Documentos/Publicaciones/2013/9180> Acesso em: 20 ago. 2013.

ARAMBULO, Primo et al. La venta de alimentos en la vía pública en América Latina. Boletín panamericano de la revista de sanidad de la oficina sanitaria Internacional. Washington D. F., v. 118, n. 2, p. 97-107, 1995.

BAYONA, Martín. A. Evaluación microbiológica de alimentos adquiridos en la vía pública en un sector del norte de Bogotá. Revista Actualidad E Divulgación Científica, Bogotá, v. 12, n. 2, p. 9-17, jul./dic. 2009.

BEZERRA, Aída Couto Dinucci. Alimentos de rua no Brasil e saúde pública. São Paulo: Annablume, 2008. 
BICUDO, Edison Claudino Junir. O Circuito Superior Marginal: produção de medicamentos e o território brasileiro. 2006. 305 p. Dissertação (Mestrado em ciências) - Departamento de Geografia. Faculdade de Filosofia, Letras e Ciências Humanas. Universidade de São Paulo, São Paulo.

BOGOTÁ. Política Distrital de Salud Ambiental para Bogotá D. C. 2011-2023. Documento Técnico Línea de Intervención Alimentos Sanos y Seguros. Bogotá, nov. 2011.

BORJA, Henry Orozco; BARRETO, Idaly; SÁNCHEZ, Vanessa. Actitudes del vendedor ambulante de la localidad de Chapinero frente a sus condiciones laborales y políticas. Diversitas: perspectivas de psicología. Bogotá, v. 4, n. 2, p. 279-290. 2008.

BRASIL. Lei n. 8.078, de 1990. Dispõe sobre a proteção do consumidor e dá outras providências. set.1990. Disponível em: <http://www.planalto.gov.br/ccivil_03/leis/l8078.htm> Acesso em: 27 jan. 2013.

BRASIL. Emenda constitucional. Altera o artigo $6^{-}$da Constituição Federal, alterando e incluindo a alimentação como direito social. v. 32, n. 64, p. 408, fev. 2010.

BRASIL. Política Nacional de Alimentação e Nutrição (PNAN). Ministério de Saúde. Brasilia, DF, 2012. CÁMARA DE COMERCIO DE BOGOTÁ - CCB. Balance del aprovechamiento económico del espacio público y las ventas callejeras. 2009a. Disponível em: <http://camara.ccb.org.co/documentos/4416_ balance_del_aprovechamiento_economico_1.pdf>Acesso em: 5 jan. 2013.

CÁMARA DE COMERCIO DE BOGOTÁ - CBB. Propuestas para el aprovechamiento económico del espacio público con énfasis en las ventas callejeras. 2009b. Disponível em:<http://www.sdp.gov.co/ portal/page/portal/PortalSDP/OrdenamientoTerritorial/EspacioPublico/DireccionTallerEspacio\%20 P\%FAblico/PublicacionesEspacioPublico/memorias/propuesta.pdf> Acesso em: 5 jan. 2013.

CARDOSO, Ryzia de Cassia Vieira; SANTOS, Sandra María Chaves; SILVA, Edleuza Oliveira. Comida de rua e intervenção: estratégias e propostas para o mundo em desenvolvimento. Ciência \& Saúde Coletiva, Rio de Janeiro, v. 14, n. 4, p. 1.215-1.224, 2009.

CODHES - Consultoría para los Derechos Humanos y el Desplazamiento. De la seguridad a la prosperidad democrática en medio del conflicto. Bogotá, 2012. Disponível em: <http://www.codhes.org/ index2.php?option=com_docman\&task=doc_view\&gid=216\&Itemid=50>Acesso em: 5 jan. 2013.

COLOMBIA. Ley n. 1480 de 2011. Por la cual se expide el Estatuto del Consumidor, el cual entra a regir dentro de seis meses, es decir, tendrá vigencia a partir del 12 de abril de 2012. Disponível em: <http://www.mercadeoclarauribe.com/descargas/nuevoestatutodelconsumidor.pdf> Acesso em: $1^{\mathrm{o}}$ fev. 2013

COSTARRICA, María de Lourdes; MORÓN, Cecilia. Estrategias para el mejoramiento de la calidad de los alimentos callejeros en América Latina y el Caribe. Oficina Regional de la FAO para América Latina y el Caribe. FNA/ANA 17/18, 1996.

CVE - Centro de Vigilância Epidemiológica. Surtos de DTA por semana epidemiológica e municípios notificados a DDTHA/CVE, ano 2010. Disponível em: <http://www.cve.saude.sp.gov.br/htm/hidrica/ hidri_estat.html> Acesso em: $1^{\circ}$ dez. 2012.

DANE - Departamento Administrativo Nacional de Estadística. SDP. Proyecciones de población por localidades para Bogotá. 2000-2015. 2009. Disponível em: <http://www.dane.gov.co/index. php?option=com_content\&view=article\&id=75\&Itemid=72> Acesso em: 25 nov. 2012.

DANE - Departamento Administrativo Nacional de Estadística. Principales indicadores del mercado laboral por departamentos, 2010. Bogotá, D. C., 2011.

DI NUCCI, Josefina Di. Circuitos de la economía urbana de bebidas gaseosas y aguas saborizadas: Consumo, discursos light y publicidad en Argentina. Revista Colombiana de Geografía, Bogotá, v. 20, n. 1, p. 103-119, 2011. 
ENSIN - Encuesta Nacional de la Situación Nutricional en Colombia 2010. Bogotá, D. C. Disponível em: <http://www.icbf.gov.co/portal/page/portal/PortalICBF/NormatividadGestion/ENSIN1/ ENSIN2010/LibroENSIN2010.pdf> Acesso em: 10 dez. 2012.

FAO - Organización de las Naciones Unidas para la Alimentación y la Agricultura. Las ramificaciones sociales del sector informal de alimentos. 2010. Disponível em: <http://www.fao.org/docrep/013/ il124pt/i1124pt02.pdf> Acesso em: 17 maio 2012.

FAO/OMS - Organización de las Naciones Unidas para la Alimentación y la Agricultura y Organización Mundial de Salud. Garantía de la inocuidad y calidad de los alimentos: diretrices para el fortalecimiento de los sistemas nacionales de control de los alimentos - Estudio. Alimentos y Nutrición 76. 2003. Disponível em: <ftp://ftp.fao.org/docrep/fao/006/y8705s/y8705s00.pdf > Acesso 13 mar. 2013.

FAO/OPS — Organización de las Naciones Unidas para la Alimentación y la Agricultura y Organización Panamericana da la Salud. Informe del Seminario - Taller Latinoamericano sobre Control de Alimentos que se venden en las Calles. (RLAC/94/07/NUT-57). Montivideo, Uruguay. 1994.

FOLHA DE S. PAULO. Barraca de chefs abre discussão sobre a proibição à comida de rua em São Paulo. Publicado: 18 de abril de 2012. Disponível em: <http://wwwl.folha.uol.com.br/comida/1077346-barraca-de-chefs-abre-discussao-sobre-a-proibicao-a-comida-de-rua-em-sao-paulo.shtml> Acesso em: 20 abr. 2013.

FLOREZ, John Trujillo; MAZUERA, María Eugenia del Hierro. Curso modular. Epidemiología Básica. Universidad de Antioquia. Tercera Edición 1998.

GARCIA, Rosa Wanda Diez . Reflexos da globalização na cultura alimentar: considerações sobre as mudanças na alimentação urbana. Revista de Nutrição, Campinas, v. 16, n. 4, dez. 2003.

GARCÍA-UBAQUE, Juan; RIAÑO-CASALLAS, Martha; BENAVIDES-PIRACÓN, John. Informalidad, desempleo y subempleo: un problema de salud pública. Revista de salud pública, Bogotá D. C., sup. 14, n. 1, p. 138-150, 2012.

GERMANO, Pedro Manuel Leal; GERMANO, Maria Izabel Simões. Higiene e vigilância sanitária de alimentos. São Paulo: Livraria Varela, 2011.

GORGULHO, Bartira Mendes. Alimentação fora do lar e sua relação com a qualidade da dieta de moradores do município de São Paulo: Estudo ISA - Capital. 2012. 80 p. Dissertação (Mestrado em ciências) - Departamento de Nutrição. Faculdade de saúde pública, Universidade de São Paulo, São Paulo.

IBGE - Instituto Brasileiro de Geografia Estadística. Censo demográfico 2010a. Disponível em: <http://www.ibge.gov.br/home/estatistica/populacao/censo2010/default.shtm> Acesso em: 20 out. 2012.

IBGE — Instituto Brasileiro de Geografia Estadística. Pesquisa de Orçamentos Familiares 2008-2009. Análise do Consumo Alimentar Pessoal no Brasil. 2010b. Disponível em: <http://www.ibge.gov.br/ home/estatistica/populacao/condicaodevida/pof/2008_2009_analise_consumo/pofanalise_2008_2009. pdf> Acceso em: 14 out. 2011.

IPE - Instituto de Economia Social de Bogotá. La Gestión del Ipes en el 2012. Disponível em: <http://www.ipes.gov.co/vercont.php?id=923> Acesso em: 15 dez. 2012.

LANGE, Tarcila Neves. Avaliação do laudo de inspeção como instrumento de verificação das condições higiênicas sanitárias de estabelecimentos varejistas de carnes do município de Ribeirão Pires. 2010. 183 p. Dissertação (Mestre em Saúde Pública) — Faculdade de Saúde Pública, Universidade de São Paulo, São Paulo.

LUCCA, Alessandra; TORRES, Elizabeth Aparecida Silva. Street-food: The hygiene conditions of hot-dogs sold in São Paulo, Brazil. Food Control. California, v. 17, p. 312-16, 2006. 
MÉNDEZ, Iván Alberto; BADILLO, Carlos Andrés; ORTIZ, Gabriela Parra; FACCINI, Álvaro Adolfo. Caracterización microbiológica de Salmonella en alimentos de venta callejera en un sector universitario de Bogotá, Colombia. Julio a octubre de 2010. Medicas UIS. Bucaramanga, v. 24, p. 26-33, 2011.

MENESES, Roberta Barbosa et al. O comércio de queijo de coalho na orla de Salvador, Bahia: trabalho infantil e segurança de alimentos. Revista de Nutrição, Campinas, v. 25, n. 3, p. 381-392, maio/jul. 2010.

MERCER. Cost of living survey city rankings-global overview, 2012. Disponível em: <http://www. mercer.com/articles/cost-of-living-2012> Acesso em: 18 set. 2012.

MINISTÉRIO DA SAÚDE. Sistema Nacional de Vigilância em Saúde. Relatório de situação. 5. ed. Brasília, DF, 2011.

OPS - Organización Panamericana de la Salud. Caracterización de los alimentos de riesgo expendidos en las vías públicas de Santa Fe de Bogotá, Colombia. Washington, D. C., 1992.

OPS - Organización Panamericana de la Salud. Contaminación microbiana de los alimentos vendidos en la vía pública en ciudades de América Latina y características socio-económicas de sus vendedores y consumidores. Oficina Subregional de la Organización Mundial de la Salud. 2005. Disponível em: <http://www.paho.org/spanish/Hcp/HCV/doc216.pdf> Acesso em: 16 out. 2012.

PED - Pesquisa de Emprego e Desemprego. Taxas de desemprego por tipo. Município de São Paulo. Secretaria de Planejamento e Desenvolvimento Regional. Fundação Sistema Estadual de Análise de Dados. 2010. Disponível em: <http://www.seade.gov.br/produtos/ped/> Acesso em: 16 out. 2012.

SANTOS, Milton. O espaço dividido: os dois circuitos da economia urbana dos países subdesenvolvidos. São Paulo: Editora da Universidade de São Paulo, 2002.

SÃO PAULO. Alerta epidemiológico: surtos de doenças transmitidas por água e alimentos (DTA). 2011. Prefeitura de São Paulo. Disponível em: <http://www.prefeitura.sp.gov.br/cidade/secretarias/ upload/chamadas/alerta_epidemiologico_-_2011_surtos_de_doencas_transmitidas_por_agua_e_ alimentos_1299791339.pdf> Acesso em: 16 out. 2012.

SÃO PAULO. Secretaria Municipal de Assistência Social. Plano de assistência social da cidade de São Paulo. 2010.

SDS - Secretaría Distrital de Salud. Base de datos Sistema de Vigilancia en Salud Pública. SIVIGILA. 2008-2010. 2011.

STEYN, Nelia; LABADARIOS, Demetre. Street foods and fast foods: how much do south africans of different ethnic groups consume? Ethnicity \& Disease, Arlington, v. 21, p. 462-463, 2011. Disponível em: <http://www.ishib.org/ED/journal/21-4/ethn-21-04-462.pdf> Acesso em: 15 maio 2011. TRIBUNAL DE JUSTIÇA DO ESTADO DE SÃO PAULO. Foro central-fazenda pública/acidentes. 2012. VIVA O CENTRO SÃO PAULO. Camelôs-Subsídios para o equacionamento do problema do comércio informal de rua e sua solução. Documento final do workshop: o Comércio Informal de Rua e a Requalificação do Centro de São Paulo. São Paulo, maio 1994. 